\title{
Current Concepts in the Etiology, Diagnosis, and Management of Relapsed Clubfoot
}

\author{
Sameer S Desai ${ }^{1}$, Ashish S Ranade ${ }^{2}$, Ankit B Waghela ${ }^{3}$
}

\begin{abstract}
Relapse is a recurrence of deformities in a previously corrected clubfoot. The incidence of relapse after the Ponseti method is reported between $26 \%$ and $48 \%$. The etiology of relapse can be variable. Some of the predisposing factors that are predictive of relapse are drop toe signs, a lower ratio of correction improvement, and muscle imbalance. Relapse can be broadly categorized into decreased dorsiflexion, cavus, equines, adduction, heel varus, and dynamic supination deformity. The principles to be followed in the treatment of relapsed clubfoot are-restarting foot abduction brace protocol, extended Ponseti method and/or soft tissue surgery, bony procedures, and external fixation devices. The Ponseti method can be used even in older children with relapse or after soft tissue surgery. Split tibialis anterior transfer may be required in a child with dynamic supination deformity. It should be performed in children above 3 years. Many children may require $>2$ procedures. Soft tissue surgery carries the risk of over- and under-correction. The external fixator can be used in children with scarring due to multiple surgeries and severe rigid deformities. Salvage procedures may be required in older children or syndromic clubfeet.

Conclusion: Children with clubfoot need to be followed up for a minimum of 5-6 years or maybe longer to diagnose and treat relapsed. Some feet are "deemed" to relapse. However, it is very difficult to identify these feet beforehand. An a la carte approach is required in the management of relapse and a surgeon treating these feet should be well versed with all the different procedures.

Keywords: Clubfoot, CTEV, Recurrence, Relapse.

Journal of Foot and Ankle Surgery (Asia Pacific) (2021): 10.5005/jp-journals-10040-1169
\end{abstract}

\section{INTRODUCTION}

The Ponseti method and the French functional method have an excellent success rate. However, many studies have reported variable relapse rates, $26-48 \%$. $^{1}$ There is variation in definition, evaluation, and treatment of recurrence of deformity in clubfoot. Relapse is defined as the recurrence of the deformity in previously treated and well-corrected clubfoot.

\section{Epidemiology}

Sangiorgio and colleagues, by using the survivorship model, have shown the possibility of relapse following Ponseti serial casting is around $30 \%$ at the age of 2 years, $45 \%$ at the age of 4 years, and almost $50 \%$ at 6 years of age. ${ }^{2}$ Recurrence has been reported to occur as late as 10 years of age. ${ }^{3}$ The reported rate of recurrence has a wide range. This could be attributed to how recurrence is defined. There is no clarity on the definition of relapse or recurrence. The definition of relapse or recurrence changes as per the criteria used and hence the rate of relapse is variable in different studies.

\section{Etiology of Relapse/Recurrence}

Children with a drop-toe sign have a high likelihood of relapse. The drop-toe sign involves, a resting position of the toes in plantarflexion along with no active toe extension in response to plantar stimulation of the foot. This finding was associated with the absent function of the anterior and lateral compartment muscles. $^{4}$

Various factors have been attributed to the recurrence of the clubfoot. Recurrence could have multifactorial etiology. Dietz has found that AP radiographs frequently showed incomplete correction of a medially displaced navicular and a diminished talocalcaneal angle in patients with dynamic supination of the forefoot. $^{5}$

\begin{abstract}
'Department of Orthopedics, KEM Hospital, Pune, Maharashtra, India
${ }^{2}$ Department of Orthopedics, Blooming Buds Centre for Pediatric Orthopaedics, Deenanath Mangeshkar Hospital, Pune, Maharashtra, India

${ }^{3}$ Department of Orthopaedics, Deenanath Mangeshkar Hospital, Pune, Maharashtra, India
\end{abstract}

Corresponding Author: Sameer S Desai, Department of Orthopedics, KEM Hospital, Pune, Maharashtra, India, Phone: +91 9767175344, e-mail: doctorsamdesai@yahoo.co.in

How to cite this article: Desai SS, Ranade AS, Waghela AB, et al. Current Concepts in the Etiology, Diagnosis, and Management of Relapsed Clubfoot. J Foot Ankle Surg (Asia Pacific) 2021;8(3):126-131.

Source of support: Nil

Conflict of interest: None

Some studies have proposed that a muscle imbalance may be a causative factor in the development of a relapsed deformity. Gelfer et al. have found poor evertor muscle activity to be associated with recurrent deformity. ${ }^{6}$ In another study by Moon et al., MRI showed soft tissue abnormalities such as intramuscular fat replacement and unique patterns of hypoplasia in specific muscle groups. ${ }^{7}$

Soft tissues may be of variable pliability and play a role in the recurrence. The ratio of correction improvement " $\mathrm{RCl}$ " (defined as initial Pirani score divided by the number of casts necessary to achieve the correction) value is an indicator of risk of recurrence. Patients with a lower $\mathrm{RCl}$ value of $<1$ had an odds ratio of relapse 27 times higher than those with $\mathrm{RCl}>1 .{ }^{8}$

Young age at tibialis anterior tendon transfer (TATT) is a known risk factor for the development of recurrence. ${ }^{9}$ The likelihood of the second relapse is almost $50 \%$ when TATT is done at age $<2.5$ years, the likelihood is $13 \%$ if the procedure is done after 2.5 years of age. Masrouha and Morcuende have also reported a higher rate

(c) The Author(s). 2021 Open Access This article is distributed under the terms of the Creative Commons Attribution 4.0 International License (https:// creativecommons.org/licenses/by-nc/4.0/), which permits unrestricted use, distribution, and non-commercial reproduction in any medium, provided you give appropriate credit to the original author(s) and the source, provide a link to the Creative Commons license, and indicate if changes were made. The Creative Commons Public Domain Dedication waiver (http://creativecommons.org/publicdomain/zero/1.0/) applies to the data made available in this article, unless otherwise stated. 
of recurrence with TATT procedures performed at an earlier age and hypothesized that delaying the TATT could reduce the likelihood of subsequent relapse. ${ }^{10}$ Underlying neurological conditions may be associated with the recurrence of the clubfoot. ${ }^{11}$

\section{Evaluation}

\section{Clinical Evaluation}

The evaluation should include the functional assessment and how the recurrence is affecting the function of the child. The clinical examination includes examining the child in a standing position as well as in a supine position. The examination should include palpating the head of talus, cavus, adductus, varus, checking for flexibility of the foot, the scars. It is important to examine the strength of various muscles around the ankle. Gait assessment is essential with particular attention to the position of the heel, presence or absence of supination, and adductus while walking. The evaluation should also include an assessment of the in-toeing, knee hyperextension.

There is no consensus as to the best scoring system while evaluating the recurrence of the clubfoot. Pirani and Dimeglio scores are of limited use for recurrence in children after walking age.

One of the proposed systems is the PBS score. ${ }^{12}$ This score evaluates seven items while the child is standing, walking, and in a sitting position. There are passive and active criteria. This score adds functional components such as active dorsiflexion, early heel rise, and walking supination. However, its role in choosing a treatment remains limited.

\section{Imaging}

Though clinical examination constitutes the backbone of the treatment plan, radiographs may impart additional information. Various angles, presence or absence of arthritic changes, presence or absence of flat top talus may help in decision making. Typically, weight-bearing anteroposterior and lateral radiographs of the foot and a supine lateral radiograph in maximum dorsiflexion are obtained. In complex deformities or older children, a CT scan is of help to assess the deformity.

\section{TREATMENT}

Typically, the relapsed clubfoot will present with either a single or a combination of the following deformities-decreased dorsiflexion, equinus, adduction, heel varus, cavus, and dynamic supination deformity. A relapsed clubfoot can be classified by using the Pirani or Dimeglio score. Eidelman et al. have classified it as early relapse (from 6 months till 30 months of age), late relapse (from 30 months to 8 years), and relapse in adolescents (9 years and older). ${ }^{13}$ Bhaskar and Patni have identified five different patterns of relapse and proposed a classification system. He has classified them into type 1a: decreased ankle dorsiflexion, with dorsiflexion not possible beyond neutral. Type $1 \mathrm{~b}$ : dynamic forefoot adduction or supination. Type 2a: rigid equinus, where dorsiflexion is not possible up to neutral. Type $2 \mathrm{~b}$ : rigid adduction of forefoot/midfoot complex, and grade III: the combination of two or more deformities: Fixed equinus, varus, and forefoot adduction. However, the limitation of these classifications is that they do not guide the management of relapsed clubfoot. The surgeon is thus left to his own discretion and experience. ${ }^{14}$ The following step-by-step approach should be used in the management of relapse.
- Restarting foot abduction bracing protocol.

- Extended Ponseti protocol-recasting or modified Ponseti method which includes repeat tendon Achilles tenotomy, open tendon Achilles lengthening, and TATT. ${ }^{15}$

- Soft tissue surgery and/or external distraction devices (Table 1).

\section{Foot Abduction Brace (FAB) Protocol}

As per Ponseti protocol, a foot abduction brace (FAB) is to be worn for 23 hours for the first 3 months and then 12 hours every day for 2-4 years. Not wearing FAB for a stipulated time has been shown to cause relapse. ${ }^{16}$ If we find that the child is crying excessively after wearing the splint, the heel is not touching the footplate after brace wear or the foot is coming out of the brace, then we should suspect early relapse. Parents should be counseled by the treating surgeon and the importance of the brace in preventing relapse should be emphasized. If the standard brace is not tolerated by the child, then alternative braces like Dobbs brace or other dynamic FAB should be prescribed. ${ }^{17}$ A newer abduction dorsiflexion mechanism brace can be used which consists of an alternative abduction, end rotation, dorsiflexion mechanism. It is constructed without a bar between both feet and therefore can be used in a single leg. A standard ankle-foot orthosis (AFO) should not be prescribed as it is less effective in preventing relapse. ${ }^{18} \mathrm{~A}$ positive communication style should be used so that parents understand that brace wear is the most important part of treatment. ${ }^{19}$ Also, a culturally sensitive educational style should be used. This has been shown to improve brace compliance and thus decrease the relapse rate. Brace wear protocol needs to be repeated in case the child undergoes the repeat Ponseti method or soft tissue release. In some children, brace wear needs to be continued till 5-7 years. In a child with complex clubfoot, the abduction angle in FAB needs to be decreased from $70^{\circ}$ to $40^{\circ}$.

\section{Ponseti Method for Relapsed Clubfoot}

The steps of correction remain the same even in a child with relapsed clubfoot. Depending on the deformity that has relapsed we should plan our plasters. For a child with a relapse of all deformities, we will first start by correcting the cavus by elevating the head of the first metatarsal. This is followed by the abduction of the foot by applying pressure over the head of the talus. Even in an older child, it is better to give an above-knee cast. If dorsiflexion $>15^{\circ}$ is not achieved then a percutaneous tendon Achilles tenotomy is planned..$^{20,21}$ The authors preferred method is to do this procedure under anesthesia in the operation theater. This has many advantages. The child will not resist the procedure and it becomes easy for the surgeon. Due to previous

Table 1: Take-home message

- The relapse rate in clubfoot after the Ponseti method is from 18 to $48 \%$.

- Baby not tolerating FAB is one of the earliest symptoms of relapse

- Repeat TA tenotomy can be performed 12 weeks after the first tenotomy.

- Ponseti method can be performed in children following recurrence after open surgery.

- There is no upper age limit for the Ponseti method.

- Soft tissue procedures have a risk of both under- and overcorrection.

- Long-term follow-up is required to diagnose and treat all relapses. 
scar tissue, there is a lot of fibrosis. Identifying completeness of tenotomy may be difficult. The neurovascular bundle is very close and some authors have also reported the presence of neuromas due to previous surgery. If in doubt we can also perform a mini-open surgery, deliver the tendon outside the skin, and complete the tenotomy. We can check the lateral tibio-calcaneal angle under the image intensifier. This angle has been reported as a very important predictor of relapse. ${ }^{22,23}$ Children with a high angle indicate the presence of ankle and subtalar joint contracture in addition to a tight TA. If we feel that it is high, then we can perform ankle and subtalar capsulotomy under the same anesthesia. The ideal interval between two tendon Achilles tenotomies should be 12 weeks as this is the time required for the tendon to reform. ${ }^{24}$

Van Praag et al. have studied children who were treated by recasting by Ponseti method following recurrence and they have found $74 \%$ of the recurrent group had a successful result at the time of follow-up. Control subjects and patients did not differ in the percentage of feet that were plantigrade and most were in valgus. However, the dorsiflexion achieved was less in relapsed feet. They have stated that after 1 or 2 episodes of casting for recurrence, further casting is unlikely to achieve success. ${ }^{3}$ Mahan et al. have also noted that in patients who sustained at least an initial recurrence, $51 \%$ sustained a second recurrence. They also observed that in those feet in which only casting was done after the first recurrence, $75 \%$ of feet recurred, while $54 \%$ of feet in which only TA lengthening was performed recurred. This shows that some feet are "deemed" to recur. In a child where relapse occurs after 2 percutaneous tenotomies, open soft tissue release is the treatment of choice of the authors. ${ }^{25}$

Many times relapsed feet have a forefoot cavus deformity. This contributes to the equinus deformity. This can be checked by measuring the Meary's angle (talo-1st metatarsal angle in the lateral view) which is normally zero. We must also differentiate an idiopathic clubfoot from a complex or atypical clubfoot. Complex clubfoot has a deep crease medial crease, the foot is short and has stubby toes and the first metatarsal is often flexed. ${ }^{26} \mathrm{~A}$ Ponseti II maneuver in which we dorsiflex the first and the fifth toe with counter pressure over the dorsum of the neck of the talus is used. These feet may require an early TA tenotomy. Do not over abduct the foot. The abduction angle in FAB should also be decreased to $40^{\circ}$. In some older children, the cavus deformity may be resistant to serial stretching. In these children, we may have to release the superficial plantar fascia in the arch of the foot. However, in more severe cases, a Steindler stripping in which the entire origin of the short flexors of the foot is stripped off the calcaneus may be required. ${ }^{27}$

\section{Posterior Release and Posteromedial Soft Tissue Release $^{13}$}

An a la carte approach is used depending on the deformities. We shall discuss the salient points and difficulties that one will encounter in a previously operated foot. The incisions taken are either a Turco posteromedial incision or a Cincinnati incision. In the presence of a previous scar, we always prefer to take the same incision taken by the previous surgeon. The neurovascular bundle is sometimes difficult to identify due to the scarring. The other structures have also undergone fibrosis and hence difficult to identify. More often than not the interosseous tibiofibular ligament needs to be cut. This is due to the deformation of the talar dome in older children. Lateral column shortening procedures are required in many children. In relapsed clubfoot, the plaster needs to be applied for a longer time. It is good to check for wound healing as there is a chance of wound dehiscence in these children.

\section{Lateral Column Shortening Procedures}

In the presence of a curved lateral border, the surgeon may prefer to do a lateral column shortening procedure. ${ }^{28}$ Cuboid decancellation or cuboid osteotomy is performed in children $<4$ years. Other procedures like Litchblau procedure and Evan procedure have been described, but they are not our preferred method of treatment as it is known to cause stiffness. When a wedge resection osteotomy of the cuboid of $>10^{\circ}$ is performed then there is a risk of hypertrophy of the base of the fifth metatarsal. Wedge excision of the distal calcaneum of up to $30^{\circ}$ can be done without much complication.

In patients where subtalar correction of the calcaneal deformity is not achieved, heel varus (calcaneal inversion combined with adduction) persists. The Dwyer osteotomy or Evans procedure has been described for treating the calcaneal varus. Dwyer osteotomy involves an extra-articular medial opening wedge calcaneal osteotomy at age $2.5-3$ years. ${ }^{29}$

Evans procedure involves a medial and posterior release and a lateral column shortening osteotomy via wedge-shaped resection at the calcaneocuboid joint. ${ }^{30,31}$

Typically, bony surgeries are reserved for older children ( $>10$ years of age) and the cartilaginous tissues may not achieve fusion and the foot size may remain small in the growing child. On the contrary, Shingade et al. have described a technique of dorsolateral closing wedge osteotomy, in children between the 5 years and 13 years age group. The osteotomy involves cuboids and the cuneiforms and is combined with percutaneous tendon Achilles tenotomy and plantar fascia release and $\mathrm{K}$ wire fixation. ${ }^{32}$

\section{Management of Fixed Adduction Deformity}

In case the foot shows a fixed adduction deformity in the absence of dynamic supination deformity, then a lateral closed wedge and a medial open wedge osteotomy can be performed. A lateral bone wedge is removed from the cuboid and inserted in the medial open wedge of the middle cuneiform. If the bone graft is small then autologous bone graft or iliac crest bone graft can be used. Staples or $\mathrm{k}$ wires can be used for internal fixation. ${ }^{28}$

\section{Dorsal Subluxation of the Navicular}

This can happen at the time of open surgery or a few years following it. Though this condition is rare, the navicular will appear inversely triangular. This shortens the medial border of the foot, causes cavovarus deformity, supinates the foot, and may cause pain over the dorsum of the foot. It can be treated by realigning the talonavicular joint by releasing the talonavicular joint capsule and calcaneocuboid joint capsule and fixing it with " $\mathrm{K}$ " wires.

\section{Avascular Necrosis (AVN) of the Talus}

With extensive peritalar release, avascular necrosis (AVN) of the talus has been reported on long-term follow-up. It causes a short stiff foot. Triple arthrodesis or talectomy in association with lateral column lengthening is the treatment of choice in symptomatic feet.

\section{Dorsal Bunion}

This is seen in older children who have undergone soft tissue release. They have weak tendon Achilles, peroneus longus, and overactive flexor hallucis longus (FHL), tibialis anterior. In symptomatic children, some authors have transferred the FHL to the neck of the first metatarsal through a drill hole. In stiff feet, we 
may have to perform a first metatarsal plantarflexion osteotomy. If the tibialis anterior is overactive then the child may require a tibialis anterior transfer.

\section{Supramalleolar Osteotomy}

In cases with severe flat top talus or incongruent stiff ankle joints, a supramalleolar osteotomy can be used for equines correction. This osteotomy is used as a salvage procedure for children with severe clubfeet. A multiplanar supramalleolar osteotomy has also been used in complex rigid deformities. ${ }^{33,34}$

\section{Anterior Tibial Hemiepiphysiodesis}

The principle is the same as a supramalleolar osteotomy that was performed earlier for an equinus deformity. Though a gradual decrease in anterior distal anterior tibial angle is seen a significant improvement in ankle dorsiflexion may not be seen. Certain recent reports however have shown some promise, especially in rigid equinus. ${ }^{35}$

\section{Tibialis Anterior Tendon Transfer ${ }^{36}$}

Dynamic supination deformity is one of the late relapses seen in clubfoot. Clinically it is tested by asking the child to dorsiflex the foot when the child is sitting on a chair. If along with dorsiflexion there is a supination component then the tibialis anterior is overactive. In the initial stages, the foot will be correctable. In later stages, the foot can become stiff. Ponseti recommends a TATT in such symptomatic children above 2.5 years. The preferred method of transfer is the entire tendon of the tibialis anterior to the lateral or intermediate cuneiform. Some authors have also transferred it to the cuboid. Split TATT is also performed in some institutes as a full transfer has a risk of overcorrection. One can make a small drill hole using a burr in the cuneiform and the tendon is passed using a whiplash suture and is sutured over the sole using a sponge and a button. Additional soft tissue procedures can be carried out if necessary. This is followed by a cast for 6 weeks and nighttime use of AFO for 2-4 years. After surgery, an improvement in eversion strength is seen in all these children. This procedure has been shown to restore balance fully in $87 \%$ and partial balance in $11 \%$ of patients. Even after this procedure, there is a chance of recurrence in $15-40 \%$ feet. Hence, these children must be followed up for a long time.

\section{Salvage Procedures}

Triple arthrodesis may be required in stiff and painful feet. Talectomy may be required in arthrogrypotic feet. These procedures are required in syndromic and neurogenic clubfoot. Penny has described a modified Lambrinudi type triple arthrodesis. In this method, all the components of the deformity are acutely corrected and a plantigrade foot is achieved. ${ }^{37}$

\section{Management of Relapse in Noni-idiopathic Clubfoot}

Non-idiopathic clubfoot has a $30-50 \%$ incidence of relapse after the Ponseti method. The incidence is higher in children with arthrogryposis as compared to meningo-myelocoele. While the repeat Ponseti method can be tried, one should have a low threshold for TATT as it is required in around $90-100 \%$ of children. Some feet may also require soft tissue release. ${ }^{38}$

The goal of all these procedures is to have a stable plantigrade foot, with minimal stiffness and functional range of motion. An orthopedic surgeon treating relapse should be well versed in all these procedures so that he can give the best result to the child.

\section{Role of External Fixators}

The treatment of recurrent clubfoot that is not responding to Ponseti serial casting or the foot that has undergone multiple procedures poses multiple challenges such as wound breakdown, wound healing, vascular problems, and incomplete correction. The common indications to use external fixation are feet with extensive scarring from previous surgeries, severe rigid deformities that are recalcitrant to treatment. While choosing an external fixator treatment, one must consider patient factors such as the ability of the patient to visit for frequent follow-ups, acceptability of the family for the external fixator device, and surgeon factors like familiarity and comfort level of the treating surgeon with the device.

Severe, recalcitrant deformities can be treated by using an external fixator. There are two broad treatment categories-(A) external fixator used for soft tissue distraction (joint sparing) and (B) external fixator combined with an osteotomy (joint invasive).

\section{External Fixator without Osteotomy (Joint-sparing Procedures)}

In this modality, the principle of soft tissue distraction is used to correct the various complement of the deformity. This method is applicable in children younger than 8 years of age.

One of the commonly used external fixator systems is Joshi's external stabilization system (JESS). In this modality, the principle of controlled differential distraction is used. It involves more distraction on the medial side compared to the lateral side. The JESS fixator principle is different from the llizarov method and does not need accurate placement of hinges. Also, the JESS system is not constrained and does not use tensioned wires. ${ }^{39-41}$

The Ponseti principle has been combined with the llizarov apparatus. In this method, an olive wire is passed through the talus. The olive acts as the thumb in the Ponseti method and during the initial phase, the forefoot adduction and cavus are corrected. While this correction happens, the talar wire is fixed to the tibial ring. Once forefoot correction is achieved, the talar wire is fixed to the foot ring and the equinus is corrected. The Ponseti inspired corrections are done using either an llizarov-type ring fixator or the use of a Taylor spatial frame. ${ }^{42,43}$

In some cases, serial Ponseti casting can be used to correct the adductus and cavus. The residual equinus can be corrected with an llizarov type of external fixator. This type of external fixator involves placing a hinge at the center of rotation of the ankle joint and a constrained frame system.

\section{External Fixator with Osteotomy/Osteotomies \pm Soft Tissue Release}

In children, older than 8 years, only soft tissue distraction is not sufficient to achieve the correction. A combination of osteotomies and soft tissue release needs to be combined with the llizarov principle to correct the deformity. ${ }^{44-47}$

The principles involve the creation of a stable tibial block and a foot frame followed by placement of various hinges and motors to gradually correct all the components of the deformity. The precise placement of hinges can be challenging. Commonly used fixator types are llizarov or Taylor Spatial Frame. Taylor's spatial frame uses the principle of the virtual hinge. When using the six-axis correction system Taylor Spatial Frame, the rings can be used in different configurations such as the Miter frame or Butt frame to correct various deformities. ${ }^{48}$ 
Severe deformities need complex osteotomies like U-osteotomy or midfoot V osteotomy. Complex osteotomy combined with the placement of a six-axis correction system is used to gradually correct the deformity. ${ }^{49,50}$

\section{References}

1. Hosseinzadeh P, Kiebzak GM, Dolan L, et al. Management of clubfoot relapses with the Ponseti method: results of a survey of the POSNA members. J Pediatr Orthop 2019;39(1):38-41. DOI: 10.1097/ BPO.0000000000000953.

2. Sangiorgio SN, Ebramzadeh E, Morgan RD, et al. The timing and relevance of relapsed deformity in patients with idiopathic clubfoot. J Am Acad Orthop Surg 2017;25(7):536-545. DOI: 10.5435/JAAOS-D16-00522.

3. van Praag VM, Lysenko M, Harvey B, et al. Casting is effective for recurrence following Ponseti treatment of clubfoot. J Bone Joint Surg Am 2018;100(12):1001-1008. DOI: 10.2106/JBJS.17.01049.

4. Edmonds EW, Frick SL. The drop toe sign: an indicator of neurologic impairment in congenital clubfoot. Clin Orthop Relat Res 2009;467(5):1238-1242. DOI: 10.1007/s11999-008-0690-9.

5. Dietz FR. Treatment of a recurrent clubfoot deformity after initial correction with the Ponseti technique. Instr Course Lect 2006;55: 625-629.

6. Gelfer $Y$, Dunkley M, Jackson D, et al. Evertor muscle activity as a predictor of the mid-term outcome following treatment of the idiopathic and non-idiopathic clubfoot. Bone Joint J 2014;96B(9):1264-1268. DOI: 10.1302/0301-620X.96B9.33755.

7. Moon DK, Gurnett CA, Aferol H, et al. Soft-tissue abnormalities associated with treatment-resistant and treatment-responsive clubfoot: findings of MRI analysis. J Bone Joint Surg Am 2014;96(15):1249-1256. DOI: 10.2106/JBJS.M.01257.

8. Zhao D, Li H, Zhao L, et al. Prognosticating factors of relapse in clubfoot management by Ponseti method. J Pediatr Orthop 2018;38(10):514-520. DOI: 10.1097/BPO.0000000000000870.

9. Luckett MR, Hosseinzadeh P, Ashley PA, et al. Factors predictive of the second recurrence in clubfeet treated by ponseti casting. J Pediatr Orthop 2015;35(3):303-306. DOI: 10.1097/BPO.0000000000000248.

10. Masrouha KZ, Morcuende JA. Relapse after tibialis anterior tendon transfer in idiopathic clubfoot treated by the Ponseti method. J Pediatr Orthop 2012;32(1):81-84. DOI: 10.1097/BPO.0b013e31823db19d.

11. Lovell ME, Morcuende JA. Neuromuscular disease as the cause of late clubfoot relapses: report of 4 cases. lowa Orthop J 2007;27:82-84.

12. Böhm S, Sinclair MF. The PBS score - a clinical assessment tool for the ambulatory and recurrent clubfoot. J Child Orthop 2019;13(3):282292. DOI: $10.1302 / 1863-2548.13 .190077$

13. Eidelman M, Kotlarsky P, Herzenberg JE. Treatment of relapsed, residual, and neglected clubfoot: adjunctive surgery. J Child Orthop 2019;13(3):293-303. DOI: 10.1302/1863-2548.13.190079.

14. Bhaskar A, Patni P. Classification of relapse pattern in clubfoot treated with Ponseti technique. Indian J Orthop 2013;47(4):370-376. DOI: 10.4103/0019-5413.114921.

15. Ponseti IV. Relapsing clubfoot: causes, prevention, and treatment. lowa Orthop J 2002;22:55-56.

16. Zhao D, Liu J, Zhao L, et al. Relapse of clubfoot after treatment with the Ponseti method and the function of the foot abduction orthosis. Clin Orthop Surg 2014;6(3):245-252. DOI: 10.4055/cios.2014. 6.3.245.

17. Desai L, Oprescu F, DiMeo A, et al. Bracing in the treatment of children with clubfoot: past, present, and future. lowa Orthop J 2010;30:15-23.

18. Janicki JA, Wright JG, Weir S, et al. A comparison of ankle-foot orthoses with foot abduction orthoses to prevent recurrence following correction of idiopathic clubfoot by the Ponseti method. J Bone Joint Surg Br 2011;93(5):700-704. DOI: 10.1302/0301-620X.93B5.24883.

19. Morin ML, Hoopes DM, Szalay EA. Positive communication paradigm decreases early recurrence in clubfoot treatment. J Pediatr Orthop 2014;34(2):219-222. DOI: 10.1097/BPO.0000000000000080.
20. Nogueira MP, Ey Batlle AM, Alves CG. Is it possible to treat recurrent clubfoot with the Ponseti technique after posteromedial release?: a preliminary study. Clin Orthop Relat Res 2009;467(5):1298-1305. DOI: 10.1007/s11999-009-0718-9.

21. Al-Hilli $A B$. Ponseti method in the treatment of post-operative relapsed idiopathic clubfoot after posteromedial release. A short term functional study. Foot (Edinb) 2020;45:101721. DOI: 10.1016/j. foot.2020.101721.

22. Shabtai L, Hemo Y, Yavor A, et al. Radiographic indicators of surgery and functional outcome in Ponseti-treated clubfeet. Foot Ankle Int 2016;37(5):542-547. DOI: 10.1177/1071100715623036.

23. Kang S, Park SS. Lateral tibiocalcaneal angle as a determinant for percutaneous achilles tenotomy for idiopathic clubfeet. J Bone Joint Surg Am 2015;97(15):1246-1254. DOI: 10.2106/JBJS.0.00076.

24. Mangat KS, Kanwar R, Johnson K, et al. Ultrasonographic phases in gap healing following Ponseti-type Achilles tenotomy. J Bone Joint Surg Am 2010;92(6):1462-1467. DOI: 10.2106/JBJS.I.00188.

25. Mahan ST, Spencer SA, May CJ, et al. Clubfoot relapse: does presentation differ based on age at initial relapse? J Child Orthop 2017;11(5):367-372. DOI: 10.1302/1863-2548.11.170016.

26. Ponseti IV, Zhivkov M, Davis N, et al. Treatment of the complex idiopathic clubfoot. Clin Orthop Relat Res 2006;451:171-176. DOI: 10.1097/01.blo.0000224062.39990.48.

27. Matar HE, Beirne P, Bruce CE, et al. Treatment of complex idiopathic clubfoot using the modified Ponseti method: up to 11 years follow-up. J Pediatr Orthop B 2017;26(2):137-142. DOI: 10.1097/ BPB. 0000000000000321.

28. McHale KA, Lenhart MK. Treatment of residual clubfoot deformity-the "bean-shaped" foot--by opening wedge medial cuneiform osteotomy and closing wedge cuboid osteotomy. Clinical review and cadaver correlations. J Pediatr Orthop 1991;11(3):374-381. DOI: 10.1097/01241398-199105000-00017.

29. DWYER FC. Osteotomy of the calcaneum for pes cavus. J Bone Joint Surg Br 1959;41-B(1):80-86. DOI: 10.1302/0301-620X.41B1.80.

30. Evans D. Calcaneo-valgus deformity. J Bone Joint Surg $\mathrm{Br}$ 1975;57(3):270-278. DOI: 10.1302/0301-620X.57B3.270.

31. Evans D. Relapsed clubfoot,.J Bone Joint Surg Br 1961;43B(4):722-733. DOI: 10.1302/0301-620X.43B4.722.

32. Shingade V, Shingade R, Ughade S. Correction of neglected or relapsed clubfoot deformity in an older child by single staged procedure-early results. Curr Ortho Pract 2012;23(2):122-129. DOI: 10.1097/BCO.0b013e318245202e.

33. Napiontek M, Nazar J. Tibial osteotomy as a salvage procedure in the treatment of congenital talipes equinovarus. J Pediatr Orthop 1994;14(6):763-767. DOI: 10.1097/01241398-199414060-00014.

34. Nelman K, Weiner DS, Morscher MA, et al. Multiplanar supramalleolar osteotomy in the management of complex rigid foot deformities in children. J Child Orthop 2009;3(1):39-46. DOI: 10.1007/s11832-0080157-2.

35. Al-Aubaidi Z, Lundgaard B, Pedersen NW. Anterior distal tibial epiphysiodesis for the treatment of recurrent equinus deformity after surgical treatment of clubfeet. J Pediatr Orthop 2011;31(6):716-720. DOI: 10.1097/BPO.0b013e31822109b6.

36. Park SS, Kim SW, Jung BS, et al. Selective soft-tissue release for recurrent or residual deformity after conservative treatment of idiopathic clubfoot. J Bone Joint Surg Br 2009;91(11):1526-1530. DOI: 10.1302/0301-620X.91B11.22327.

37. Penny JN. The neglected clubfoot. Tech Orthop 2005;20(2):153-166. DOI: 10.1097/01.bto.0000162987.08300.5e.

38. Morcuende JA, Dobbs MB, Frick SL. Results of the Ponseti method in patients with clubfoot associated with arthrogryposis. lowa Orthop J 2008;28:22-26.

39. Suresh S, Ahmed A, Sharma VK. Role of Joshi's external stabilization system fixator in the management of idiopathic clubfoot.J Orthop Surg (Hong Kong) 2003;11(2):194-201. DOI: 10.1177/230949900301100216.

40. Devadoss A, Devadoss S, Kapoor A. Differential distraction for relapsed clubfoot deformity in children. J Orthop Surg (Hong Kong) 2010;18(3):342-345. DOI: 10.1177/230949901001800317. 
41. Dhawan M, Rana N. Management of neglected, recurrent, and resistant congenital talipes equinovarus by controlled differential fractional distraction using the Joshi's external stabilization system. Curr Med Res Pract 2019;9(2):176-181. DOI: 10.1016/j. cmrp.2019.08.002.

42. Tripathy SK, Saini R, Sudes P, et al. Application of the Ponseti principle for deformity correction in neglected and relapsed clubfoot using the Ilizarov fixator. J Pediatr Orthop B 2011;20(1):26-32. DOI: 10.1097/ BPB.0b013e32833f33fe.

43. Ganger R, Radler $C$, Handlbauer $A$, et al. External fixation in clubfoot treatment - a review of the literature. J Pediatr Orthop B 2012;21(1):5258. DOI: 10.1097/BPB.0b013e32834adba7.

44. Grant $A D, A \operatorname{tar} D$, Lehman WB. The llizarov technique in correction of complex foot deformities. Clin Orthop Relat Res 1992(280):94-103. DOI: 10.1097/00003086-199207000-00012.

45. Grill F, Franke J. The llizarov distractor for the correction of relapsed or neglected clubfoot. J Bone Joint Surg Br 1987;69(4):593-597. DOI: 10.1302/0301-620X.69B4.3611163.
46. Ferreira RC, Costa MT. Recurrent clubfoot--approach and treatment with external fixation. Foot Ankle Clin 2009;14(3):435-445. DOI: 10.1016/j.fcl.2009.03.009.

47. Kocaoğlu M, Eralp L, Atalar AC, et al. Correction of complex foot deformities using the Ilizarov external fixator. J Foot Ankle Surg 2002;41(1):30-39. DOI: 10.1016/s1067-2516(02)80007-2.

48. Lamm BM, Standard SC, Galley IJ, et al. External fixation for the foot and ankle in children. Clin Podiatr Med Surg 2006;23(1):137-166. , ix 10.1016/j.cpm.2005.10.007 Erratum in. Clin Podiatr Med Surg 2006;23(2):485-6.

49. Gourdine-Shaw MC, Lamm BM, Paley D, et al. Distraction osteogenesis for complex foot deformities: U-osteotomy with external fixation. J Bone Joint Surg Am 2012;94(15):1420-1427. DOI: 10.2106/JBJS. K.00360.

50. Lamm BM, Gourdine-Shaw MC, Thabet AM, et al. Distraction osteogenesis for complex foot deformities: Gigli saw midfoot osteotomy with external fixation. J Foot Ankle Surg 2014;53(5):567576. DOI: 10.1053/j.jfas.2014.04.008. 